\title{
SENAM PROLANIS DM DAN JALAN KAKITERHADAPPENURUNAN KADAR GULA DARAH PADA PENDERITA DIABETES MELLITUS TIPE II DI KLINIK UMP PURWOKERTO
}

\author{
Agus Sutiono $^{1}$ Dedy Purwito ${ }^{2}$ \\ Fakultas Ilmu Kesehatan Program Studi Sarjana Keperawatan Universitas \\ Muhammadiyah Purwokerto
}

Jl. Raya Dukuh Waluh, PO BOX 202, Purwokerto 53182, Kembaran Banyumas, Ind onesia sutiono322@gmail.com

\begin{abstract}
Abstrak
Diabetes mellitus merupakan salah satu penyakit degeneratif kronik. Prevalensi penderita terus meningkat tiap tahunnya, salah satu terapi non-farmakologi adalah olah raga seperti senam prolanis DM serta jalan kaki untuk menurunkan kadar gula darah melalui peningkatan pemakaian glukos oleh otot tubuh saat latihan. Penelitian ini untuk mengetahu pengaruh efektivitas senam prolanis DM dan jalan terhadap penurunan kadar gula darah pada pasien DM tipe II. Penelitian ini mengunakan meto de Quasi experiment menggunakan pre-post with two group design. Populasi penelitian adalah berjumlah 92 penderita DM tipe II dengan sampel sebanyak 82 orang. Pengumpulan data mengunakan Glukometer (Auto check blood glucose monitor). Analisa statistik menggunakan uji wilcoxon. Penelitian menunjukan nilai $\mathrm{p}=0.002$, senam prolanis DM artinya ada pengaruh signifikan terhadap penurunan kadar gula darah pasien diabetes mellitus tipe II. Sedangkan jalan kaki menunjukan nilai p-value $=0.001$, dari uji statistis Wilcoxon Signed Rank Test di dapatkan hasil korelasi $Z=7.866$, artinya ada pengaruh kuat senam prolanis DM dan jalan kaki terhadap penuru nan kadar gula darah pasien diabetes milutus tipe II. Kegiatan olah raga yang teratur, terukur dan benar dapat di pertimbangkan sebagai terapi non-farmakologi bagi penderita diabetes mellitus tipe II un tuk menurunkan kadar gula darah.
\end{abstract}

Kata kunci : Senam prolanis (DM), jalan kaki, kadar gula darah

\begin{abstract}
Diabetes mellitus is one of cronical degenerative disease. The prevalence of sufferers continues to increase every year, one of the non-pharmacological therapies is exercise such as gymnastics prolanis DM and walking exercises to decrease the glucose level by the body muscles during the physical body. This research is to find out the effectiveness of Prolanis and walking exercises in reducing blood sugar levels in DM patients type II. This study uses the Quasi experiment with pre and post with two group design. The study population was 92 DM patients type II with a sample of 82 people. Glucometer (Auto check blood glucose monitor) is used to collect the data. Wiloxon Test is used to analyze the statistical data. The research shows that the value of Prolanis Exercises (DM) is $p=0.002$ which means a significant influence on decrease of the sugar level of DM patients type II. Meanwhile the value of walking exercises is $p=0.001$. From the statistic test of WIlconxon Signed Rank Test, It obtained $Z$ correlation $=7.886$. It means that there is a significant correlation betwe en Prolanis and walking exercises towards the decrease of blood sugar level of Diabetes Mellitus patients type II. Physical activities done regularly, measurably, and correctlyare suggested to be considered as nonpharmacological therapies for Diabetes Mellitus patients type II to decrease blood sugar level.
\end{abstract}

Keywords: Prolanis Exercises (DM), Walking, sugar blood level.

\section{PENDAHULUAN}

Peningkatan jumlah penderita secara signifikat terus mengalami kenaikan akhir-akhir ini bahkan sangat cepat. Penderita diabetes mellitus belum menyadari betapa bahaya penyakit ini. Hal ini disebabkan karena beberapa penderita tanpa merasakan gejala dari penyakit tersebut seperti; rasa haus berlebih, sehingga penderita meminum air banyak; sering buang air kecil. Selain itu, berat badan seseorang juga menurun, serta rasa lapar belebih namun semakin banyak makan malah

Corresponding author:

Agus Sutiono

Sutiono322@gmail.com 
semakin lemas badan pendererita bukan semakin segar serta kuat (Herlambang, 2012).

WHO merilis pada tahun 2014 terdapat 244 milyar penduduk di dunia menderita DM dan pada tahun 2018 mencapai 279,3milyar orang, dan di perkirakan di tahun 2025 jumlah penderita DM bisa mencapai 333 s/d 366 milyar jiwa. Indonesia saat ini berada di urutan ke empat di dunia Negara dengan penderita DM terbanyak di dunia $8,4 \%$ data lain menyebutkan bahwa mulai tahun 2014 , terdapat sedikitya $63,5 \%$ penyebab kematian segala umur di dunia adalah karena penyakit tidak menular (Kemenkes, 2016).

Angka pervalensi penderita DM di propinsi Jawa Tengah yang tergantung dengan obat insulin pada tahun 2015 seban yak 8.611 kasus. Penderita Diabetes Mellitus di Kabupaten Banyumas sendiri di temukan 9.315 kasus, Kabupaten Cilacap 2.905, Kabupaten Purbalingga 2.309 dan di Kabupaten Banjar Negara 1.858 kasus, sedangkan jumlah penderita DM tipe II yang di kelola oleh klinik UMP sebanyak 45 orang (BPJS KESEHATAN, 2019).

Senam atau latihan jasmani di samping menjaga kebugaran tubuh juga dapat berfungsi sebagai terapi kontrol kadar gula dalam darah. Senam prolanis adalah senam fisik yang di rancang menurut usia dan status fisik dan merupakan dari proses pengobatan diabetes mellitus. Pada waktu latihan jasmani o tot-otot tubuh, system jantung dan sirkulasi darah serta pernafasan di aktifkan. Oleh sebab itu metabolism tubuh, keseimbangan cairan dan elektrolit serta asam basa harus menyesuaik an diri. Otot-otot akan mengunakan as am lemak bebas dan glukosa sebagai sumber tenaga atau energy. Bila latihan jasmani dimulai glukosa yang berasal dari glukogen di otot-otot pada latihan jasmani mulai di pakai sebagai sumber energy. Apabila latihan jasmani terus ditingkatakan maka sumber energy dan glikogen otot berkurang, selanjutnya akan terjadi pemakaian glukosa darah dan asam lemak bebas. Makin ditingkatkan porsi latihan makin meningkat pula pemakaian glukosa yang berasal dari cadangan glikogen hepar. Apabila ditingkatkan lagi,maka sumber energy terutama berasal dari asam lemak bebas dan lipolisis jaringan lemak (PERSADIA, 2012).

Klinik UMP Purwokerto sebagai salah satu instansi layanan kesehatan tingkat dasar ikut berperan aktif dalam program; promotif, preventif, kuratif dan rehabilitative. Salah satunya adalah dalam penangganan penyakit tidak menular kususnya penyakit DM, dalam penatalaksaannya untuk mengontol kadar gu la darah di laksanakan dengan dua cara yaitu ; pertama penatalaksaan DM dengan farmakologi dan yang kedua penatalaksanan dengan non-farmakologi.

Penatalaksanaan non-farmakologi yang biasa di lakukan di klinik UMP Purwokerto salah satunya adalah dengan mengadakan senam prolanis khusus bagi penderita DM yang di lakukan seminggu sekali. Dengan dasar latar belakang tersebut maka penelitian ini dilakukan dengan tujuan untuk mengetahui "Pengaruh senam prolanis DM dan jalan kaki terhadap penurunan kadar gula darah pada penderita Diabetes mellitus tipe II di klinik UMP Purwokerto".

\section{METODE PENELITIAN}

Penelitian ini merupakan penelitian kuantitatif menggunakan desain quasi experiment dengan rancangan pre and post test with control group design. Penelitian dengan menggunakan dua kelompok subyek yaitu kelompok perlakuan dan kelompok kontrol. Sampel untuk kelompok intervensi senam prolanis DM sejumlah 41 orang, sedangkan pada kelompok kontrol jalan kaki seju mlah 41 orang. Variabel bebas dalam penelitian ini adalah senam prolanis dan variabel terikat pada penelitian ini adalah kadar gula darah. Intervensi pada kelompok kontrol diberikan senam prolanis DM dan kelompok kontrol diberikan intervensi jalan kaki. Instrumen yan g digunakan lembar observasi dan seperangkat Glucotest untuk mengukur kadar gula darah responden, tape recorder/soundsystem untuk melakukan senam prolanis. Kelompok kontrol melakukan jalan kaki selama senam prolanis berlangsung \pm 30- 45 menit. Senam prolanis dilakukan sebanyak 1 kali dalam satu minggu. Analisa ini mengunakan uji statistik wilcoxon

\section{HASIL}

Penelitian dilakukan di Klinik UMP Purwokerto. Penelitian dilakukan pada tanggal 16 November 2019 sampai dengan 7 desember 2019. Responden pada penelitian ini adalah peserta prolanis di klinik UMP Purwokerto yang menderita DM tipe II. Jumlah responden yaitu 82 orang yang dibagi dalam kelompok senam prolanis dan kelompok jalan kaki santai. 
1. Analisis Univariat: Gambaran karakteristik responden

Tabel 1

Karakteristik Responden Berdasarkan Usia

\begin{tabular}{|c|c|c|c|c|}
\hline \multirow[b]{2}{*}{ Karakteristik Responden } & \multicolumn{2}{|c|}{ Kelompok senam prolanis } & \multicolumn{2}{|c|}{ Kelompok jalan kaki } \\
\hline & Frekuensi & Persentase & Frekuensi & Persentase \\
\hline \multicolumn{5}{|l|}{ Umur (tahun) } \\
\hline $36-45$ & 6 & 14,6 & 6 & 14,6 \\
\hline $46-55$ & 10 & 24,4 & 20 & 48,8 \\
\hline $56-65$ & 22 & 53,7 & 13 & 31,7 \\
\hline$>-65$ & 3 & 7,3 & 2 & 4,9 \\
\hline \multicolumn{5}{|l|}{ Jenis Kelamin } \\
\hline Laki-laki & 18 & 43,9 & 19 & 46,3 \\
\hline Perempuan & 23 & 56,1 & 22 & 53,7 \\
\hline \multicolumn{5}{|l|}{ Pendidikan } \\
\hline SD & 2 & 4,9 & 3 & 7,3 \\
\hline SMP & 8 & 19,5 & 15 & 36,6 \\
\hline SMA & 22 & 53,7 & 18 & 43,9 \\
\hline $\mathrm{D} 3 / \mathrm{S} 1$ & 9 & 22,0 & 5 & 12,2 \\
\hline \multicolumn{5}{|l|}{ Status pekerjaan } \\
\hline PNS & 7 & 17,1 & 1 & 2,4 \\
\hline Swasta & 9 & 22,0 & 13 & 31,7 \\
\hline Petani & 10 & 24,4 & 8 & 19,5 \\
\hline Pedagang & 4 & 9,8 & 12 & 29,5 \\
\hline TNI/POLRI & 2 & 4,9 & 2 & 4,9 \\
\hline Lain-lain & 9 & 22,0 & 5 & 12,2 \\
\hline Jumlah & 41 & 100,0 & 41 & 100,0 \\
\hline
\end{tabular}

Sumber: Data Primer Terolah Desember 2019

Tabel 1 menunjukkan bahwa kisaran rerata usia kedua kelompok adalah 54,7 tahun,usia yang paling muda 36 tahun dan usia yang paling tua 69 tahun, berdas arkan jenis kelamin pada kelompok senam prolanis paling banyak perempuan $23(56,1 \%)$ di banding laki-laki $18(43,9 \%)$ dan kelo mpok jalan kaki paling banyak perempuan 22 $(53,7 \%)$ di banding laki-laki sebesar

2. Analisa Bivariat

a. Gambaran skor kadar gula darah sebelum dan sesudah dilakukan senam prolanis

Pengaruh senam prolanis (DM) terhadap penurunan kadar gula darah dapat di lihat pada table di bawah ini.

Tabel 2

Skor Kadar Gula Darah Sebelum Dan Sesudah Senam Diabetes

\begin{tabular}{ccc}
\hline $\begin{array}{c}\text { Waktu } \\
\text { Pengukuran }\end{array}$ & $\begin{array}{c}\text { Kadar Gula Darah } \\
\text { (mean } \pm \text { SD) }\end{array}$ & $\begin{array}{c}\text { P } \\
\text { Value }\end{array}$ \\
\hline Pre test & $213.51 \pm 81.82$ & 0.002 \\
Post test & $71.41 \pm 74.79$ & \\
\hline
\end{tabular}

Tabel 2 menunjukan bahwa secara statistic ada pengaruh yang signifikan dari kegiatan senam prolanis (DM) terhadap penurunan nilai kadar gula darah di tunjukan
19(46,3\%). Berdasarkan pekerjaan pada kelompok senam prolanis paling banyak adalah petani $(24,4 \%)$ sedangkan pada kelompok jalan kaki paling banyak pekerjaanya adalah swasta $13(31,7 \%)$, pendidikan paling banyak pada kelompok senam prolanis SMA sebesar 22(53,7\%) dan pada kelompok jalan kaki adalah SMA sebesar $18(43,9 \%)$

dengan nilai $\mathrm{P}$ Value $=0.002$ pada penderita DM tipe II.

b. Gambaran skor kadar gula darah sebelum dan sesudah di lakukan jalan kaki

Pengaruh jalan kaki terhadap penurunan kadar gula pada penderita DM tipe II dapat di lihat pada table di bawah ini

Tabel 3

Skor Kadar Gula Darah Sebelum Dan Sesudah Jalan Kaki

\begin{tabular}{lll}
\hline $\begin{array}{l}\text { Waktu } \\
\text { Pengukuran }\end{array}$ & $\begin{array}{l}\text { Kadar Gula } \\
\text { Darah } \\
(\mathbf{m e a n} \pm \text { SD) }\end{array}$ & P Value \\
\hline Pre test & $253.41 \pm 81.82$ & \\
Post test & $181.71 \pm 74.79$ & 0.001 \\
\hline
\end{tabular}

Tabel 3 menunjukan bahwa ada pengaruh yang signifikan dari kegiatan jalan kaki terhadap penurunan kadar gula darah 
bagi penderita DM tipe II sebesar P Value $=$ 0.001

c. Perbedaan senam prolanis (DM) dan jalan kaki terhadap penurunan kadar gula darah bagi penderita DM tipe II

Perbedaan pengaruh senam prolanis (DM) dan jalan kaki terhadap penurunan kadar gula darah pada pendetita DM tipe II dapat di lihat pada tabel di bawah ini.

\section{Tabel 4}

Perbedaan Senam Prolanis (DM) Dan Jalan Kaki

\begin{tabular}{lcc}
\hline $\begin{array}{c}\text { Kelompok } \\
\text { Intervensi }\end{array}$ & $\begin{array}{c}\text { Kadar Gula } \\
\text { Darah } \\
\text { (mean } \pm \text { SD) }\end{array}$ & $\begin{array}{c}\text { P } \\
\text { Value }\end{array}$ \\
\hline Senam & $185.59 \pm 17.93$ & 0.68 \\
prolanis(DM) & $195.56 \pm 23.62$ & \\
Jalan kaki & & \\
\hline
\end{tabular}

Tabel 4 di atas menunjukan bahwa tidak ada perbedaan yang signifikan dari nilai mean kadar gula darah pada kelom pok senam prolanis (DM) dan jalan kaki di tunjukan dengan nilai $\mathrm{P}$ Value $=0.68 \mathrm{pada}$ penderita DM tipe II.

\section{PEMBAHASAN}

Pembahasan pada bagian ini mengenai hasil dari penelitian yang telah dilakukan y aitu tentang "pengaruh senam prolanis DM dan jalan kaki terhadap penurunan kadar gula darah pada penderita DM tipe II di klinik UMP Purwokerto"

Hasil studi Smeltzer \& Bare (2014) menyatakan bahwa penyandang terbanyak DM dialami oleh penderita yang berusia 40 tahun, hal ini karena retensi insulin pada DM cenderung meningkat pada usia 46-65 tahun.

Hasil penelitian menunjukan bahwa dari 82 responden yang terdiri dari 41 responden dengan senam prolanis dan 41 responden dengan jalan kaki sebelum di intervensi terdapat $70 \%$ kadar gulanya pada interval 250 280 dan terjadi penurunan kadar gula darah setelah di intervensi sebagian besar res pon den $75 \%$ (36 responden) pada senam prolanis (DM) dan 70\% (30 responden) pada jalan kaki. Dari uji statistis Wilcoxon Signed Rank Test didapatkan hasil 1 ( $\alpha$-hitung) $=0.000$ dan korelasi $Z=7.866$, artinya ada pengaruh kuat senam dan jalan kaki terhadap penurunan kadar gula darah pada pasien diabetes mellitus tipe II. Ini sependapat dengan penelitian Rizanian sy ah et. all (2015).
Hasil penelitian ini menunjukan bahwa terdapat perbedaan antara kadar gula darah sebelum dan sesudah kegiatan senam prolan is (DM) dengan P-Value $=0.002$, dimana kadar gula padamasa sebelum kegiatan senam prolani (DM) lebih tinggi dari pada sesudah kegiatan senam prolanis (DM). Rodrigo et. all (2015) menyebutkan bahwa senam diabetes mellitus berperan dalam pengaturan kadar glukosa darah karena glukosa otot yang sedang bekerja dapat mencapai kenaikan 15-20 kali lipat akibat peningkatan laju metabolic pada otot yang aktif dan hal ini dapat membakar lemak tak jenuh, meningkatkan sensitivitas insulin sehingga akan menurunkan glukosa darah. Selain bermanfaat dalam mengontrol kadar gula darah senam prolanis (DM) juga berfungsi mengontrol kelebihan berat badan yang tidak ideal (Siti, 2017).

Penelitian Jalan kaki untuk penderita DM tipe II, menunjukan hasil yang signifikan dimana terdapat perbedaan kadar gula darah sebelum dan sesudah di lakukan jalan kaki sebesar nilai $\mathrm{P}$ Value $=0.001$. Jalan kaki merupakan jenis olah raga ringan yang mudah di lakukan oleh siapa saja dan dimana saja dan sangat bermanfaat bagi penderita diabetes mellitus tipe II dalam membantu mengontrol kadar gula darah (Rehmaita, et. all. 2015).

Witriyani (2017) menyebutkan bahwa individu dengan penyakit diabetes mellitus tipe II yang melakukan kegiatan jalan kaki mengalami penurunan rata-rata kadar gula darah sebanyak $50 \mathrm{mg} / \mathrm{dl} / \mathrm{tahun}$. Syed, et. all (2019) menyebutkan bahwa kegiatan jalan kaki santai sejauh $2 \mathrm{Km}$ dengan waktu tempuh 30 menit dapat menurunkan kadar gula secara bermakna pada penderita diabetes mellitus. Jalan kaki secara teratur 3-4 kali seminggu selam kurang waktu 30 menit dapat memperbaiki profil lemak, menurun kan berat bardan dan menjaga kebugaran, juga penting untuk meningkatkan sensitivitas terhadap insulin, sehingga akan menurunkan kadar gula darah (Perkeni, 2011).

Hasil penelitian ini menunjukan bahwa tidak ada perbedaan yang berarti antara rerata kadar gula darah pada kegiatan senam prolanis (DM) dan jalan kaki pada penderita diabetes mellitus tipe II. Hal ini mengeindikasikan bahwa kegiatan olah raga yang di lakukan secara teratur,benar dan terukur akan membantu menstabilkan kadar gula darah dan membantu 
mengurangi kebutuhan insulin serta bisa mengontrol berat badan yang berlebihan.

\section{KESIMPULAN}

Kegiatan aktifitas fisik baik senam prolanis (DM) maupun jalan kaki sangat baik dilakukan oleh penderita diabetes mellitus tipe II untuk membantu menurunkan kadar gula darah. Namun dari hasil analisis yang paling baik dalam menurunkan kadar gula darah adalah senam prolanis (DM). Kegiatan yang dilakukan secara baik, terukur dan teratur akan membantu menstabilkan kadar gula darah, mengurasi ketergantungan terhadap insulin, mengontrol pengunaan lemak tak jenuh dan mengidealkan berat badan. Serta mengurangi ketergantungan terhadap obat-obatan dan menciptakan suasana hidup yang din amis dan berfungsi secara optimal.

Penderita DM tipe II di harapkan dapat melakukan kegiatan olah raga senam prolanis(DM) atau jalan kaki secara rutin, benar, teratur dan terukur sebagai sarana menurunkan kadar gula darah dan men gontrol berat badan tubuh secara non-farmakologi yang tidak ada efek sampingnya dan tidak ketergantungan pada insulin sebagai terapi farmakologi saja.

Penelitian ini menambah wawasan dan pengetahuan serta dapat di jadikan acuan dalam penyusunan buku dan pedoman gerakan sen am dan petunjukan melakukan senam prolanis (DM) secara benar.

Penelitian ini dapat di jadikan pedoman pengelolaan pasien penyakit kronis di Klinik UMP Purwokerto dalam pemberian terapi nonfarmakologi sehingga penderita tidak tergantung terapi farmakologi selama hidupnya.

\section{DAFTAR PUSTAKA}

BPJS KESEHATAN. (2019). Kejadian Diabetes Melitus. BPJS Kesehatan.

Herlambang. (2012). Menaklukkan Hipertensi dan Diabetes. Yogyakarta: Tugu Publisher.

Kemenkes RI. (2016). Riset Kesehatan Dasar 2016. Jakarta : Kemenkes RI

PERSADIA. (2012). Pedoman Senam Diabetes Seri 5. Unit RS. dr. Marzuki Mahdi Bogor.
Rehmaita, et. all. (2015). Pengaruh Senam Diabetes Dan Jalan Kaki Terhadap Penurunan Kadar Gula Darah Pada Pasien Dm Tipe II Di Puskesmas Krueng Barona Jaya Aceh Besar. Jurnal Keperawatan, 5 (2).

Rizaniansyah et. all. (2015). Senam kaki diabetes menurunkan kadar gula darah pasien diabetes mellitus tipe II . Jurnal Ners Community, 6 (2).

Rodrigo S., et. all. (2015). The role of aerobic training variables progression on glycemic control of patients with tipe 2 diabetes : a systematic revie w with meta-analysis. Sport Medicine Open, 7;5(1):22 doi: 10.1186/s40798-019$0194-z$.

Siti M. S. (2017). Pengaruh Senam Diabetes Millitus terhadap kadar gula darah Pada penderita diabetes mellitus tipe II di wilayah kerja Puskesmas Gamping I Sleman Yogyakarta. Jurnal Keperawatan. Diakses 2019

Smeltzer, S. C., dan Bare Brenda, B.G. (2014). Buku Ajar Keperawatan Medikal. Bedah vol 4 (9 th ed.). Jakarta : EGC.

Syed S. et. all. (2019). Response to a Supervised Structured Aerob Exercise Training Program in Patients with Type 2 Diabetes Mellitus e Does Gender Make a Difference?A Randomized controlled Clinical Trial. Journal of the National Medical Association, $110 \quad$ (5) DOI: 10.1016/j.jnma.2017.10.003

Witriyani, (2017). Efektifitas senam diabetes mellitus dalam menurunkan kadar gula darah pada penderita diabetes mellitus di wilayah kerja puskesmas kayumas. Jurnal Keperawatan, 6 (2). 